\title{
Entrevista com Heather Lotherington e Cheryl Paige
}

\author{
Hércules Tolêdo Corrêa \\ Universidade Federal de Ouro Preto - UFOP - Minas Gerais - Brasil
}

Carla Viana Coscarelli

Universidade Federal de Minas Gerais - UFMG - Minas Gerais - Brasil

Introdução: Toronto, no Canadá, é uma das cidades mais multiculturais do mundo. Suas escolas públicas costumam receber alunos de diferentes nacionalidades, ascendências, etnias, religiões e culturas, o que pode dificultar bastante os processos de ensino e aprendizagem. Nesta entrevista, as duas especialistas canadenses falam da produtiva parceria que estabeleceram, durante cerca de 10 anos, com objetivo de melhorar o ensino na Joyce Public School, escola situada no noroeste da cidade, na região de York. Com isso demonstram a importância do trabalho conjunto entre os especialistas das universidades e os professores da escola pública. Quem mais ganhou com essa pesquisa foram os professores e os alunos.

Heather Lotherington é professora, pesquisadora e diretora associada da Faculdade de Educação da York University, em Toronto, Canadá. É ph. D. em Educação pela University of Toronto. Seus interesses de pesquisa são o ensino/aprendizagem de línguas, mediado pela tecnologia, em ambiente multicultural e multilinguístico. Em sua produção acadêmica, em meio a muitos artigos e papers, destacam-se os livros: Pedagogy of Multiliteracies: Rewriting Goldilocks (Pedagogia dos Multiletramentos: reescrevendo Goldilocks) (Routlege, 2011) e Teaching Young Learners in a Superdiverse World: Multimodal Approaches and Perspectives (Ensinando jovens aprendizes em um mundo superdiverso: abordagens multimodais e perspectivas) (Routledge, 2017), co-editado com Cheryl Paige. Os dois livros constituem a apresentação dos resultados da pesquisa-ação colaborativa realizada na Joyce Public School.

Cheryl Paige é mestre em Educação pela University of Toronto, foi diretora da Joyce Public School e atualmente é consultora de Tecnologia Educacional no Toronto District School Board. 
Hércules Corrêa (HC) e Carla Coscarelli (CC):

Professoras, sabemos que a pesquisa-ação na Joyce Public School (JPS) durou cerca de 10 anos e que teve resultados muito positivos, pois a escola saiu de uma condição em que não alcançava níveis desejáveis de proficiência dos alunos em leitura (apenas 24\% dos alunos tinham habilidades mínimas, conforme as avaliações sistêmicas da Província de Ontario) e também em outras áreas (como a matemática, em que os alunos apresentavam um índice de 39\% de habilidades mínimas com a disciplina) e alcançou excelentes resultados ao final, com o recebimento de muitos prêmios e reconhecimento regional, nacional e até internacional. Gostaríamos de saber até que ponto essa modalidade de pesquisa - pesquisa-ação longitudinal, de longa duração, e em cooperação universidadeescola - é comum no Canadá. Como aconteceu de uma professora da York University chegar até a JPS? como foram as primeiras negociações e os primeiros anos da pesquisa (envolvimento de professores, alunos, funcionários e pais)?

Heather Lotherington $(\mathrm{HL})$ :

O tipo de trabalho que fizemos com a JPS se baseia muito na ideia de que você trabalha em conjunto com as partes interessadas em uma questão local e na qual todas as pessoas têm uma grande participação. Você trabalha em conjunto para resolver um problema. Como sempre, estamos limitados pelo dinheiro. Mesmo assim fomos capazes de nos manter unidos, juntando pequenas doações. Não havia o prazo que se tem com pesquisas de políticas governamentais, que the dão, por exemplo, dois anos para mostrar um produto. Então, uma das coisas que aprendemos com essa experiência foi que precisávamos fazer algo. Poderia não funcionar da primeira vez, mas era preciso descobrir por que não deu certo, atacar esse motivo e tentar novamente. Na verdade, precisávamos aprender. Estávamos tentando fazer uma coisa nova, se não desse certo, tentaríamos novamente, analisando o que fizemos e como aconteceu.

A pesquisa-ação longitudinal com a cooperação universidade-escola não é tão comum no Canadá. Nós podemos nos considerar pioneiros. Tentamos uma metodologia que cresceu e se transformou, ao invés de apenas aplicar alguma metodologia que vem de fora, em termos de pesquisa. Agora esse tipo de pesquisa está se tornando mais comum e há uma revista canadense sobre pesquisa-ação, que publica resultados de pesquisas semelhantes ao tipo de trabalho que fizemos, o The Canadian Journal of Action Research, que está disponível para consulta e leitura gratuitas na internet. Esse tipo de trabalho não era comum quando começamos, há cerca de dezoito anos.

Em relação a como cheguei na JPS e como foram as primeiras negociações e os primeiros anos na pesquisa, foi o seguinte. Às vezes a vida vai em direções inusitadas e engraçadas. Eu fui apresentada à escola por meio de outra pesquisa. Fui convidada pelo Professor Ron Owston, um grande pesquisador da Universidade de York, que trabalha com tecnologia e projetos de aprendizagem, para ser sua colaboradora em uma pesquisa. Então ele me disse: "Por que você não se junta a nós e eu vou lhe mostrar nossa cultura de pesquisa aqui". Ele foi muito generoso, e havia oportunidade de eu visitar e conhecer escolas em todo o Canadá. Mas minha situação na época deixava essas viagens extras um pouco pesadas para mim, então eu escolhi as escolas locais e fui apresentda à JPS por meio desse projeto, assim como também a outras escolas públicas de Toronto. Foi então que ficamos completamente impressionados com a distância entre as universidades e as escolas fundamentais. As duas escolas públicas eram cenários escolares que tinham crianças pobres, que não tinham muito dinheiro, crianças que eram na sua maioria recém-chegadas ao Canadá, em situação de risco, crianças que precisavam de mais compreensão e obtiveram essa atenção em escolas ousadas, que foram caracterizadas por terem uma diretoria muito atuante e terem programas digitais. Eram escolas "aventureiras", no bom sentido, não tinham nada a perder e tinham tudo a ganhar. $O$ que aconteceu posteriormente foi que eu estava procurando um contexto para minha própria pesquisa e, não tendo muito sucesso, acabei por encontrar um professor naqueles primeiros dias que me convidou para ir à escola. Fui lá e encontrei muito acolhimento, conheci a diretora, a Senhora Cheryl Paige, que está aqui conosco neste momento. Ela foi muito receptiva e me disse: "Venha trabalhar aqui conosco." Então, comecei a fazer esse trabalho com essa escola. 
Cheryl Paige (CP):

Eu gostaria de acrescentar algo. A Profa. Heather Lotherington estava vindo de uma perspectiva de educação universitária, com o objetivo de orientar "bons professores" e uma medida de nosso sucesso não era apenas "como as crianças faziam", mas "o que os professores estão fazendo". Hoje, mais da metade daqueles professores que trabalharam conosco está em alguma posição de liderança. Esse impacto precisa ser considerado. Eu percebi que, na verdade, nossa maior conquista foi o impacto que tivemos nos professores, de modo que eles assumissem a responsabilidade de entrar na administração, de se tornassem líderes, consultores de programas e compartilhassem o que descobrimos.

HL:

Como um movimento de base do tipo "pega e faz" Eu não sou fã de pesquisa política, no modelo top down (de cima para baixo). Daquelas em que você tem dinheiro de um órgão do governo para mostrar resultados em dois anos. Quase sempre demora muito mais do que isso para mudar a cultura da escola. Você vê o tipo de resultado que essas agências de fomento estão esperando, e, pelo pouco tempo e o tipo de projeto envolvido, não temos um registro que demonstre que o projeto foi bem sucedido, assim tão rapidamente. Não acho que esse seja a melhor maneira para realizar projetos que me interessam. Fizemos este trabalho por nós mesmos, por vontade própria. Foi isso o que aconteceu. Não podemos dizer que é uma ocorrência comum aqui no Canadá. Eu acredito que muitos pesquisadores encontram muitas portas fechadas, isso não é incomum. Mas nós tivemos a sorte de encontrar portas abertas. No início, o trabalho acontecia com um grupo de professores interessados. Cheryl teve então a ideia de mudar de um grupo voluntário, que se reunia na universidade, para um trabalho na escola, durante os dias letivos, como parte de uma cultura da escola. Ela começou a falar sobre a importância de se incorporar isso à cultura escolar, e isso realmente estava começando a acontecer. Mudamos nossas oficinas para a escola. Uma vez por mês, pela manhã, os professores se reuniam e foram chamados professores substitutos. Cheryl conseguiu financiamento e pagaria por um professor substituto para que pudéssemos conseguir professores trabalhando juntos. Os professores começaram a descobrir por si mesmos como poderiam juntar o tempo de preparação para que eles pudessem trabalhar juntos, os professores aprenderam muito rapidamente, estamos falando do trabalho deles, não do meu, muito foi da criatividade deles. Eu só tinha a estrutura que permitia que eles tivessem ideias e pudessem planejar, mas eles fizeram o trabalho. De 2002 a 2005, tivemos pequenos subsídios. Recebemos um grande financiamento em 2005, que nos levou até 2008. Nesse ano, obtivemos outro grande financiamento.

\section{$\mathrm{HC}$ e CC:}

Profa. Heather, sabemos que sua pesquisa com e na JPS gerou dois importantes e consistentes volumes, que se intitulam: Pedagogy of Multiliteracies: Rewriting Goldlocks (Routlege, 2011), (em português Pedagogia dos Multiletramentos: reescrevendo Goldilocks) e Teaching Young Learners in a Superdiverse World (Routledge, 2017), (em português Ensinando jovens aprendizes em um mundo superdiverso: abordagens multimodais e perspectivas). Gostaríamos que vocês falassem brevemente para nossos leitores o que caracteriza e o que diferencia cada um desses volumes.

HL:

Basicamente, o primeiro livro é sobre os primeiros anos de pesquisa, até 2008. Eu escrevi esse primeiro volume sozinha, é a minha voz que está lá. O segundo volume, de 2017, tem a voz de todos, é certo que interferi na edição, mas é a voz de todos que está lá e o texto foi editado para que professores, estudantes de pós-graduação e até mesmo pais pudessem falar sobre o que eles fizeram. Esse segundo livro também tem a colaboração de outra grande pesquisadora, a Profa. Dra. Jennifer Jensen, que se juntou a nós. A professora Jennifer Jensen é muito conhecida no campo do jogo e da aprendizagem digital, e ela trouxe perspectivas sobre como poderíamos incorporar as linguagens da comunidade na aprendizagem escolar, que era o que eu estava procurando, e como podemos incorporar as tecnologias digitais e as línguas e o ensino digital de forma mais imaginativa, também de uma maneira mais lúdica, o que revelou ser realmente 
importante.

No primeiro livro, detalhamos como nos divertimos com nossos grupos de voluntários, como tentamos reescrever histórias e como os professores aprenderam muito e também aceitaram muito bem minhas "ideias loucas". Eles puderam experimentá-las porque eles estavam comprometidos com seus alunos e era um contexto muito acolhedor. As pessoas queriam tentar fazer coisas interessantes, foi assim que aconteceu. Foi preciso muita cooperação. Não posso dizer que foi algo que eu fiz, foi algo que nós fizemos, nós produzimos, colaborativamente.

Sobre o trabalho com "Cachinhos Dourados e os três ursos", basicamente reescrevemos as histórias. Eu estava interessada em ver crianças reescrevendo as histórias, fazendo parte delas, em vez de estar do lado de fora. "Cachinhos Dourados e os três ursos" é um conto tradicional, como se sabe, e é uma história sobre uma pequena garota loira. Mas não havia garotas loiras na sala. Por sorte também não havia ursos (risos). Então a história não fazia muito sentido para os pequenos. Você precisa ler os contos populares com as crianças, percebendo o que é dito nas entrelinhas para saber o que a história está realmente querendo mostrar. Então, o leitor pode, pelo menos, sentir que é parte dessa história. Eu estava tentando fazer as crianças reescreverem as narrativas. Eu esperava ver as histórias nas línguas delas, na escola, e levou muito trabalho para descobrir como fazer isso. O restante foi muito fácil, as crianças adoraram a ideia de reescrever as histórias. Elas fizeram isso usando diferentes dispositivos digitais, usando fantoches de vários tipos, e vários modos diferentes. Sobre o uso de tecnologia, Cheryl Paige conseguiu uma concessão para comprar uma série de equipamentos, aí a escola tinha um pouco mais do que muitas outras escolas públicas, mas devo admitir que no Canadá, na província de Ontario, as escolas são razoavelmente bem financiadas. Mas, mesmo assim, elas nunca têm tecnologia suficiente, muitos equipamentos estão obsoletos, mas não é como se não tivéssemos nada, e temos também suportes para ter softwares.

CP:

Vamos associar esse projeto com as avaliações sistêmicas da escola pública. Uma das coisas que está na avaliação é que as crianças devem saber escrever uma história. Então reunimos os professores em uma sala e dissemos: "O que você precisa saber para contar uma história? Como incluir personagens e situações? Como resolver problemas por meio de histórias?" Muitas das crianças matriculadas, eu diria que um terço delas, não vieram de casas alfabetizadas. Então, no momento em que Heather entrou na escola, os professores das turmas iniciais, que seriam do jardim de infância até a terceira série, estavam vendo o que eles poderiam fazer para desenvolver histórias com essas classes. Estávamos trabalhando focados para que no terceiro ano as crianças escrevessem uma história que seria aceitável e considerada uma história bem desenvolvida para o nível de classificação no teste. Heather entrou e ajudou-nos a olhar de várias perspectivas diferentes.

HL:

Eu tenho uma hipótese, é apenas uma conjectura: uma das coisas que as crianças aprenderam foi ser sujeito, agente, elas aprenderam a confiar em si mesmas para resolver problemas e, portanto, concebiam um texto como um conjunto de problemas. Essa é a minha teoria, eu não tenho comprovação, mas temos algumas estatísticas. No último capítulo do livro de 2017 , falamos sobre 0 sucesso do trabalho. As pontuações da JPS aumentaram incrivelmente nos testes provinciais, mesmo que não estivéssemos a ensinar um ao outro. Não preparávamos diretamente para o teste. Porque com isso pensávamos estar instaurando o medo, gerando tensão e ansiedade.

CP:

Acho que outra coisa que fez a diferença foi que os professores se apropriaram do projeto. Como todos estavam trabalhando juntos para dar às crianças o melhor currículo possível, todos levaram isso a sério, como muita responsabilidade, e trabalharam em equipes. O que eles sabiam, em particular, em matemática, eles 
conseguiram que as crianças trabalhassem em equipe na resolução de problemas, de modo que a cultura colaborativa que começou nos multiletramentos fosse transferida para a matemática e depois fosse transferida para muitas áreas curriculares. Uma cultura escolar que está focada na escassez, a propriedade de todos é ouro, isso irá levá-los para onde você quiser. De verdade, honestamente, os professores foram muito mais longe. Os projetos foram muito mais adiante do que eles pensaram que iriam, porque nós demos a responsabilidade do sucesso da escola para os professores, e eles assumiram isso.

$\mathrm{HC}$ e CC:

No primeiro artigo do livro de 2017, Cheryl Paige menciona a dificuldade que teve de conquistar alguns professores de sua equipe com relação à importância da incorporação das tecnologias digitais em seus projetos e aulas, mencionando que muitas vezes esses professores viam a tecnologia como um "fardo a mais" em seus trabalhos. Gostaríamos que vocês falassem um pouco sobre isso. Como vocês conseguiram conquistar esses professores e fazer com que abraçassem os projetos.

CP:

Pedimos que incorporassem em seus trabalhos a tecnologia digital e também inserissem as famílias das crianças. Pedimos que cada projeto tivesse links com os pais. Nós não dissemos a eles "você precisa produzir um projeto", porque, no final, descobrimos que no processo que a aprendizagem aconteceu. Os professores tinham uma estrutura curricular e esperávamos que eles ensinassem o currículo bem e, na nossa experiência, cada professor quer ser, quase sempre, o melhor possível. Uma vez que eles começaram a trabalhar juntos, eles entenderam como poderiam se apoiar. Uma das coisas que Heather trabalhou e que realmente fez a diferença foi quando todos nos reunimos, para trabalhar conjuntamente. Imaginem, havia vinte e duas pessoas ao redor de uma mesa e elas falavam sobre seus projetos, seus grupos de trabalho. Nós sempre nos certificávamos de que os professores trabalhavam em equipes. Um de cada ano, por equipe. Eles falavam sobre seus projetos e seus desafios. Isso abriu os olhos das pessoas para os desafios que poderíamos ter em diferentes níveis. Tínhamos grupos heterogêneos, com um professor de cada nível de ensino. Essa foi uma boa alternativa porque desenvolveu um respeito pelo trabalho profissional que os professores estavam fazendo. Como havia mais tolerância, houve mais aceitação, havia mais a ideia de que estávamos juntos nisso para tornar a JPS uma excelente escola, um ótimo ambiente de aprendizagem para as crianças. Muitas vezes, quando o professor dizia "eu tenho este desafio", outro professor respondia "eu posso ajudá-lo com isso". Tínhamos cinco grades curriculares para cumprir, mas esse currículo tinha que ser divertido, tinha que ser mais atraente para os alunos.

HL:

$\mathrm{Na}$ JPS, cerca de $90 \%$ das famílias são imigrantes de primeira ou segunda geração no Canadá. Isso significa que toda sala de aula tem uma riqueza de linguagens e perspectivas culturais. Isso também significa que todo professor de sala de aula deve ser, também, um professor de inglês. Para execução dos projetos, foi preciso usar as línguas da comunidade, trouxemos as "línguas de casa". Basicamente, havia três grandes línguas das comunidades(identificar que línguas eram essas nos livros da Heather), e os professores tiveram que ser colaborativos. Era preciso trabalhar em conjunto, cobrir as grades curriculares, ensinar o que precisava ensinar, por isso foi importante. Meu objetivo de pesquisa era: eles tinham que trazer as línguas da comunidade de alguma forma para a escola, precisávamos encontrar maneiras de acolher essas línguas.

CP:

Eu também quero falar sobre isso. Encontrei a mesma resistência que qualquer administrador, qualquer líder encontra quando tenta mudar uma direção ou uma abordagem e, primeiro tivemos que mostrar algumas coisas aos professores. Tivemos que mostrar a eles que a tecnologia os ajuda a ensinar ainda melhor, tivemos que vender essa ideia e eles tiveram que ver que, para que eles 
pudessem implementá-la diretamente em sua sala de aula, nós precisávamos mudar o sistema de crenças deste lugar, e então tivemos que mostrar muitas vezes como fazer e repetir tudo várias vezes. Inicialmente, quando Heather se juntou à comunidade da JPS e vários mestrandos, estudantes de doutorado e professores entraram na escola para sentar-se ao redor da mesa com os professores, esses professores ficaram intimidados. O que vou dizer à frente da Dra. Lotherington e da Dra. Jensen, elas devem saber todas as respostas. Alguns professores são líderes e começaram, aos poucos, falando suas opiniões porque isso é bastante interessante e também tivemos as diferenças culturais entre a universidade e a escola. Eu tive que falar com os pesquisadores sobre o tipo de linguagem que eles estavam usando na escola. Eram culturas diferentes, inicialmente os professores colocaram todos esses pesquisadores em um pedestal, mas esses professores é que nos davam as respostas para tudo. O que a Heather fez foi perceber isso. Então, não era só o fato de que eles sabiam as respostas, era que, juntos, nós conseguíamos entender o problema e construir a resposta. Foi muito interessante.

\section{$\mathrm{HC}$ e CC:}

Ainda neste primeiro artigo do livro de 2017, Cheryl Paige fala do papel da música instrumental na aprendizagem das crianças da JPS, tendo ela mesma se oferecido para dar aulas às crianças à noite, com o intenso envolvimento da família. Gostaríamos de saber um pouco mais sobre esse trabalho e as relações entre música e aprendizagem de matemática e de leitura.

HL:

Realmente, é uma questão de aprender com o processo e não com o produto. Também fomos apanhados de surpresa quando um dos projetos mais fascinantes não terminou a tempo e isso se era um problema frequente. No final do ano letivo, o professor não conseguiu mostrar seu produto e os estudantes de pósgraduação que pesquisavam sobre esse projeto começaram a me questionar, o que é compreensível. Nessa época, isso foi bastante pesado. O projeto era apresentar uma ópera para as crianças. O projeto envolvia um professor de música, especialista, e o problema, basicamente, era que ele não conseguia trabalhar mais tempo durante o dia escolar porque ele era um professor itinerante. Ele só tinha um período de tempo para trabalhar com cada classe. Então, uma das coisas que os professores descobriram é que eles precisavam de um período de tempo maior. Eles tinham Matemática, Ciências Sociais e Inglês, e eles se ajuntaram esse dia e todos trabalharam juntos e usaram esse período de tempo para a aprendizagem baseada em projetos. Esse era essencialmente o problema, com o horário do professor de música. No final, o professor mostrou aos alunos ideias brilhantes de ópera, como a ópera do personagem Pernalonga (Bugs Bunny Opera), e foi da ópera chinesa à ópera-rock. Então, as crianças começaram a produzir suas próprias óperas e também produziram alguns tipos de materiais de ópera. As crianças estavam tentando aprender idiomas, suas ideias eram excelentes, o problema era o tempo de processamento, não tivemos tempo colaborativo suficiente para nos reunir e fazer isso. Esse foi um bom exemplo do que costuma acontecer

\section{CP:}

Eu sempre tive uma forte crença de que a música instrumental no início do ano faz diferença na conquista e aprendizagem. Eu estava trabalhando em uma escola onde não havia instrumentos musicais. Uma das escolas secundárias estava fechando e um dos nossos zeladores conseguiu os teclados digitais, literalmente retirados de um depósito de lixo, e os trouxe para a nossa escola e nós começamos a ensinar as crianças a ler música e a tocar músicas simples. Basicamente, não precisávamos de tantos teclados, nós tínhamos quinze teclados e podíamos colocar dois alunos em um teclado e programá-lo para que você pudesse ter duas crianças nele. Usamos musicwares software de música (ver o que é) para ajudá-los. Mas a correlação entre aprender música instrumental e aprendizagem, eu não sei bem o que é, a música é uma disciplina muito interessante, você deve seguir as regras. Você precisa começar no início da peça e tocar as notas na ordem em que devem ser tocadas e você tem que ser capaz de ler as notas em um gráfico para descobrir quais notas você deve tocar, e precisa se lembrar da melodia. É uma disciplina tão complexa, acredito. Eu li 
algumas pesquisas, uma delas de Harvard, e não há dúvida de que crianças que aprendem música instrumental (não canto coral, porque as crianças podem estar sentadas no coro cantando algumas coisas fora de sintonia e com as palavras erradas, e não ter muito problema) têm mais facilidade para aprender outras coisas. Na música instrumental, há feedback completo, você toca a nota errada e não vai soar bem. De qualquer forma, algumas das crianças estavam realmente entusiasmadas a aprender mais. Então todos tiveram uma aula de música por semana. Algumas das crianças estavam muito interessadas, então eu me ofereci para dar mais de uma aula por semana, porque eu amo música e queria fazer a diferença, já que alguns dos pais não podiam pagar aulas particulares de música para essas crianças. Eles vinham uma vez por semana e ensaiavam as peças. Com os teclados digitais podemos programar para que um grupo esteja tocando violino; outro, violoncelo e outro grupo tocando outros instrumentos. Todos usando teclados. Nós simplesmente nos divertimos muito. Isso trazia muitos benefícios. Antes, quando eu era a diretora, a maioria dos pais da minha comunidade nunca entrou na escola, eles não se sentiam confortáveis, mas eles entrariam se pudessem ter aulas de música gratuitas e assim eu conseguia conhecê-los. Em segundo lugar, havia uma barreira de linguagem, mas mesmo que não pudéssemos nos comunicar bem, pudemos nos comunicar através da música. Eles sabiam o que eu queria e eu poderia entender o que eles queriam. Em terceiro lugar, na minha escola, é necessário ter um conselho escolar constituído pelos pais e, para que ele funcionasse, era necessário que os pais entrassem na escola para participar, e eu sei que antes de fazer isso eu teria três pais, em uma escola de quatrocentos e cinquenta alunos. Muitos pais vieram e queriam informações sobre onde conseguir o uniforme da escola e não sobre 0 que estávamos fazendo. Essas pessoas estavam trabalhando, eles tinham dois empregos, muitas vezes, eles sentiram que estavam trabalhando duro colocando seus filhos lá, eles confiaram em nós para dar a seus filhos o melhor. Mas, ter esse grupo no qual gostávamos de tocar juntos, isso quebrou uma barreira na comunidade. $\mathrm{O}$ fato de eu ser uma diretora aparentemente foi considerado muito especial, a maioria dos pais ficou muito chocada com o fato de a diretora realmente fazer isso com eles, então isso quebrou o gelo e permitiu que os pais participassem da escola. Depois começamos a tirar fotos de pais e filhos e colocamos nos quadros de avisos para que eles se sentissem parte da comunidade escolar. A cultura ali era de que pais não participavam da escola, mas quebramos esse tabu e, no final, no momento em que partimos, tínhamos um conselho escolar em pleno funcionamento, em que os pais estavam tentando nos ajudar. Eles nos ajudaram com muitos dos nossos projetos, eles estavam muito orgulhosos do que estávamos fazendo, eles sentiam o pertencimento tanto em relação à escola quanto com os professores. Eles sentiram que seus filhos estavam indo para a melhor escola, eles fariam qualquer coisa para nos ajudar. Criamos essa cultura. Não era apenas eu ensinando música a eles, muitos professores passaram a ficar depois das aulas, participavam e ajudavam os pais. Eles passavam a se conhecer em um ambiente informal.

HL:

Há muitas outras coisas que podem ser ditas sobre música também, mas nós não temos condições e espaço de falar tudo nesse momento. Geralmente, a música exige que o cérebro funcione de maneira diferente de muitos dos assuntos centrados na linguagem visual que você aprende na escola. A matemática é diferente também, nela você manipula um conjunto de símbolos. A linguagem verbal também é um conjunto de símbolos. A música também é um conjunto de símbolos, mas são conjuntos de símbolos diferentes. Na música, se você toca um teclado você tem que colocar as duas mãos nele e tocar diferentes ritmos com elas, dois padrões diferentes, se você toca bateria, por exemplo, você tem quatro ritmos, você tem dois braços em ritmos diferentes, tambores ou chimbaus você toca com dois pés, e pode ter de tocar quatro ritmos diferentes ao mesmo tempo. Você pode fazer isso em uma dança, existem outros modos cinestésicos em que você pode fazer isso, mas a verdade é que não trabalhamos o suficiente com disciplinas que são frequentemente chamadas de "leves", ou disciplinas de arte na escola. Na verdade, elas não são nem um pouco leves. Elas exigem que o cérebro pense de formas diferentes. Nas artes visuais também você tem que pensar as coisas de maneira diferente.

Precisamos falar sobre as avaliações. Nos testes e nos paradigmas dos testes, em Ontário, temos uma insistência nos velhos 3R (em inglês): leitura (reading) escrita (w-riting) e aritmética (a-rithmetic). Esses são os três $\mathrm{R}$ da educação de 
massas do início do século 19. No século 21, duzentos anos depois de alguns desses movimentos para iniciar a educação em massa, nós não mudamos muito em nossa visão sobre o que é básico, e em Ontário, o que estão fazendo é exigir testes de alfabetização, que é escrever, ler, basicamente dois dos três $R$, e a matemática, que é o terceiro, a aritmética. Acho que tem também um teste de ciências no nível secundário. Então o que acontece é que a arte fica de lado, não temos a mesma dedicação à música, por exemplo. A música não está lá, eles não querem testar isso, eles querem testar se você pode escrever bem. Como uma pessoa que ensina aspectos relacionados à linguagem, eu não tenho certeza de que todos têm de saber muito sobre a linguagem verbal. Você precisa se expressar adequadamente, precisa saber a ortografia básica e assim por diante, mas nem todos precisam ser capazes de escrever um ensaio. Ou seja, há pessoas que pretendem ser mecânicos, por exemplo, e pessoas que pretendem trabalhar com as mãos, pessoas que pretendem ir às ciências duras e à matemática. Muitas pessoas realmente não têm que escrever ensaios, e então fico um pouco chateada às vezes porque insistimos em formas arcaicas de um tipo particular de letramento. Isso é uma longa conversa. O que estou dizendo é que a música é maravilhosa para o cérebro, assim como a dança, assim como o arte, e nós fazemos muito pouco disso. No caso desse projeto em particular, a música foi algo que trouxe as pessoas para a escola, o que foi ótimo.

$\mathrm{HC}$ e CC:

Professoras, sabemos que a pesquisa colaborativa com a JPS terminou por volta de 2012 e que atualmente Cheryl Paige, ex-diretora da JPS, está aposentada. Quais são as notícias que vocês têm da continuidade dos seus trabalhos na JPS e como estão as avaliações provinciais dos alunos da JPS atualmente?

$\mathrm{CP}:$

O que podemos considerar é que nosso trabalho ainda subsidiou os testes em 2013 e 2014. Depois disso, infelizmente, os resultados não foram tão satisfatórios. É possível acompanhar esses dados porque são divulgados na página da escola via Toronto District School Board: entre 2013 e 2015, com relação à leitura, os percentuais de todos os alunos do $3^{\circ}$ ano com ou acima do padrão provicial baixaram de $83 \%$ para $73 \%$; com relação à matemática, entre 2015 e 2017, os mesmos tipos de percentuais baixaram de $77 \%$ para $60 \%$. Apenas com relação à escrita os percentuais se mantiveram em 83\% entre 2014 e 2016, com relação ao padrão provincial. Mesmo assim, percebe-se que a escola se mantém acima da média dos padrões da província de Ontario.

HL:

A aprendizagem, nesse nosso projeto, centrava-se no processo, e isso aparece bem relatado no segundo livro, no capítulo 6, intitulado What if it flops? Learning as Doing (E se ele fracassar? Aprender fazendo), de Laura Mae Lindo e Cheryl Paige. Laura Lindo hoje em dia é doutora em educação e está trabalhando em uma universidade em Ontario. Ela e Cheryl escreveram esse capítulo, observando como é aprender essencialmente pelos processos. Quanto ao acompanhamento da aprendizagem, não chamaria isso de "treinamento" em toda a comunidade de aprendizado. Comunidade de aprendizado foi o nome dado por Cheryl Paige para o que chamamos de "comunidade de prática" em um processo de pesquisa-ação, e compreendia professores, pesquisadores, estudantes de pós-graduação que eram assistentes de ensino, professores de outros países em intercâmbio, pais, todas as pessoas que estavam envolvidas. Tivemos consultores do conselho que se interessaram e queriam se juntar a nós. Era uma espécie de "corpo em deslocamento", mas basicamente era a criação de um espaço seguro onde as pessoas se sentiam à vontade para conversar. Percebi que cumprimos isso, porque uma das nossas missões era trabalhar com 0 chamado "aprendizado dialógico". Estou me apropriando do teórico russo Mikhail Bakhtin, olhando para o diálogo como algo extremamente necessário, uma espécie de aprendizagem socrática, de alguma maneira. Eu queria muito fazer isso, mas as escolas eram lugares sempre muito hieráticos, muito sagrados, e então, quando começamos, eu percebia que as pessoas estavam ansiosas, olhando para mim e perguntando "o que você quer fazer?", e eu dizia algo como "nós estamos aqui para descobrir isso". Demorou bastante tempo, porque eu 
tinha de aprender o que fazer. Uma das professoras sugeriu "aprendamos, planejemos, compartilhemos". E fizemos disso uma forma de enquadramento para nossas conversas. Basicamente, chegamos ao ponto em que fizemos o seguinte: conversamos sobre material teórico, o que as pessoas teriam tempo de planejar e elas compartilhariam tudo para que pudéssemos falar sobre os problemas, as soluções, o que não deu certo, o que deu certo e coisas assim. Foi uma ótima maneira de construir a aprendizagem colaborativa. Costumávamos fazer uma apresentação e mostrar o que os professores tinham trabalhado durante $o$ ano e, num determinado ano, uma professora muito jovem, em seu primeiro ano de ensino, fez um projeto espetacular. Ela fez com que as crianças filmassem seus pais falando sobre como eles vieram para o Canadá, e as crianças fizeram filmes adoráveis. Esses filmes estão no YouTube. A TV Ontário fez um especial com eles. Alguns pequenos filmes relativos aos projetos estão disponíveis no YouTube. Sugerimos que os leitores assistam a: Imagine a World (disponível em https://www.youtube.com/watch?v=8zabcX_zoP0), dirigido por Heather Lotherington (2011, 7min25seg); Building Bridges Through Technologie at Joyce Public School (disponível em https://www.youtube.com/watch?v=569g4D-Acnl) (2012, 4min53seg) e Coming to Canada: Immigration Stories (disponível em https://www.youtube.com/watch?v=04VsndXbULw) (2011, 4min39seg).

$\mathrm{HC}$ e CC:

Percebe-se o quanto a pesquisa colaborativa foi importante para o êxito da JPS, mas notamos que houve todo um empenho da direção da escola também, bem como o investimento em tecnologia, que demandou parcerias e um bom financiamento. Como as senhoras veem a possibilidade de que outras escolas também obtenham êxitos semelhantes, considerando que há muitas variáveis a serem levadas em conta?

HL:

Outras escolas podem fazer o mesmo. Mas é preciso criar uma confiança nos próprios participantes do processo. Se você quer saber se um projeto de alfabetização e letramento como este funcionaria no Brasil do mesmo modo que funciona no Canadá, a minha resposta é que nada funciona da mesma forma em qualquer lugar, então, de uma escola para outra em Toronto haverá diferenças. Não estamos criando um molde e fazendo tudo de uma maneira uniforme. Estávamos procurando trabalhar juntos, acho que a Cheryl Paige responde isso melhor: é a cultura da escola, trabalhando juntos, trabalhando em colaboração, trabalhando para o bem das crianças. As crianças tiveram desafios que nós convertemos em oportunidades. Acredito que se você instituir esse tipo de comunidade de aprendizado e pensar sobre a escolaridade de forma diferente no Brasil, isso poderia ser feito facilmente, conforme as necessidades das escolas brasileiras. As necessidades serão diferentes e você vai precisar trabalhar de formas diferentes para atender a cada uma delas.

HC e CC:

Vemos no momento alguma divergência teórica entre os princípios e conceitos dos chamados Novos Estudos de Letramento (NLS) e os dos Multiletramentos. Como vocês percebem as diferenças e semelhanças entre esses dois quadros teóricos?

HL:

Os Novos Estudos do Letramento e os Multiletramentos basicamente estão trabalhando na mesma direção. Há pequenas diferenças que não são importantes. Em termos de minha própria aprendizagem, eu prefiro olhar para o que temos em comum do que para o que temos de diferente, para que possamos trabalhar produtivamente juntos. Acho que os novos letramentos não prestam tanta atenção à diferença de idioma nem à alfabetização básica, eles prestam muita atenção às alfabetizações digitais. Não vejo isso como sendo problemático de qualquer forma, são apenas tendências diferentes, diferentes trajetórias e estudos, penso que basicamente estamos indo na mesma direção e essa é provavelmente a melhor maneira de pensar sobre isso. 
$\mathrm{CP}:$

Quando estávamos olhando para o projeto de multiletramentos, eles tinham que ter componentes especiais, eles também tinham de se ajustar ao currículo, tinham que envolver os pais, envolver tecnologias digitais, usar as "línguas do lar", mas uma coisa que escrevemos no segundo livro, eles tinham de desenvolver 0 pensamento crítico. No mundo atual isso é absolutamente essencial, as crianças tiveram que desenvolver o pensamento crítico. Uma das maneiras que realmente ressaltamos era o ponto de vista, para que as crianças aprendessem a avaliar o que elas estavam lendo e aprendessem a construir textos em diferentes perspectivas. Esse é um critério sobre a escrita que vem da teoria dos multiletramentos.

HL:

Isso também é consistente com os Novos Estudos do Letramento, o foco no letramento crítico. Lanço esse caminho de volta ao Brasil, com Paulo Freire, na década de 1970, de modo que volta ao círculo inteiro.

$\mathrm{HC}$ e CC:

Os críticos da teoria dos multiletramentos costumam dizer que a teoria não é apropriada para países em que não se tem o multiculturalismo típico do Canadá, da França ou dos Estados Unidos, como alguns acham que é o caso do Brasil. Gostaríamos de saber o que pensam sobre essa questão.

HL:

Penso que não seja verdade, porque, antes de tudo, penso que os multiletramentos podem ser aplicados em variadas situações. Considero que a multimodalidade e a aprendizagem multimodal significam que a comunicação agora requer formas diferentes, diferentes kits de ferramentas semióticas trabalhando em conjunto e um desses kits de ferramentas são diferentes idiomas de crianças que falam línguas diferentes. Sei que o Brasil, talvez como o Japão, seja um bom exemplo de um país onde há uma espécie de "grande oceano" de uma língua. Os Estados Unidos também são um pouco assim, exceto que lá, dependendo de onde você está, há oportunidade para usar diferentes línguas, mas não em todos os lugares. Eu tive a sensação de que o Brasil, quando estive brevemente por aí, em 2017, era um vasto "mar de português", mas não tive a sensação de que era só isso. Ficou muito claro para mim que a sociedade é constituída também de imigrantes, de diferentes etnias. As datas da imigração podem ser muito diferentes, você pode ter tido o maior movimento de pessoas imigrando para o Brasil em outras épocas, mas há por aí muitas diferenças culturais. Eu consegui falar francês e espanhol no Brasil quando eu tentei comprar mantimentos. Eu simplesmente não conseguia me fazer entender em inglês e um dos caixas me disse "¿Habla usted español?" e eu respondi "Sí", e conversamos, aí consegui comprar o que queria. Em outra ocasião, estava em uma conferência, sentei-me junto a um grupo de jovens brasileiros e pensei, bem, eu estou em uma conferência internacional no Brasil, vamos conversar com alguns brasileiros e percebi que muitos falavam inglês e eles ficaram bastante felizes em usar o inglês. Mas um dos garotos sentados ao meu lado perguntou: "Parlez-vous français?" e eu disse "Oui" e conversamos em francês que, claro, tem uma semelhança maior com o português do que o inglês. Eu sei que eu estava numa grande cidade, o Rio de Janeiro, e percebei que as pessoas falavam outras línguas. Acho que estamos todos querendo falar com o mundo de modo geral. Acredito que as tecnologias digitais são uma grande parte disso. Precisamos levar isso em consideração.

CP:

A chave desse nosso projeto foi essa: nós nos relacionamos com a criança, com suas experiências e seus antecedentes. Em Toronto, nós temos a questão das várias "línguas de casa" das crianças, mas em todo o mundo as crianças têm antecedentes e experiências e o básico da boa aprendizagem é primeiro se conectar com a criança e trazer o que está na vida dela para a aprendizagem.

$\mathrm{HC}$ e CC: 
Como o Canadá e, mais especificamente, a cidade de Toronto lida com o multiculturalismo e como outros países que receberam muitos imigrantes têm lidado com essa questão?

HL:

Toronto está acostumada ao multiculturalismo e há políticas públicas para isso.

CP:

Nós não isolamos os alunos imigrantes. Eu sei que em alguns países isolam novos alunos que não falam o idioma e os colocam em escolas segregadas até que tenham adquirido alguma proficiência no idioma. Nós procuramos integrá-los imediatamente, e isso é realmente bastante interessante. Vou contar uma experiência que tive. As crianças vinham de todas as partes do mundo, tenho certeza de que tínhamos crianças do Brasil lá, e elas estavam aprendendo inglês, então, no pátio da escola, eu ouvia as versões mais estranhas do inglês, porque era uma combinação de duas ou três línguas. As crianças diziam algo como: "Eu ganhei ele", e eu falava: "Não, não, você não pode ganhar uma pessoa, você ganha um jogo". Elas estavam criando essas estruturas de frases muito estranhas, e isso também era bastante divertido.

\section{HL:}

Eu acho que não posso falar tanto sobre as políticas internacionais desse jeito. Mas o que posso dizer é que você, Hércules, teve a chance de verificar algumas das nossas formas de viver em Toronto, no momento em que esteve conosco, na York University, então talvez você esteja mais apto a falar disso. 